\title{
BUYER POWER AND THE 'WATERBED EFFECT'*
}

\author{
ROMAN INDERST $T^{\dagger} \quad$ TOMMASO M. VALLETTI ${ }^{\ddagger}$
}

\begin{abstract}
When a buyer is able to obtain lower input prices from a supplier, is it possible that other buyers will have to pay more for the same input as a result? Is this bad for consumers? We present a model that analyzes the conditions under which the asymmetric exercise of buyer power can lead to consumer detriment through raising other buyers' wholesale prices (the 'waterbed effect').
\end{abstract}

\section{INTRODUCTION}

IN SPRING 2008, THE UK'S COMPETITION COMMISSION COMPLETED its inquiry into the national grocery retail market. ${ }^{1}$ The purchasing power of the biggest retailers was one of the key issues in this inquiry, and the Commission, for the first time, also looked seriously into the possibility of a 'waterbed effect': the theory that more-advantageous terms of trade for larger or otherwise more powerful buyers could lead to worse terms for their less powerful rivals. On previous occasions, the UK's antitrust authorities had chosen not to consider the possibility of a waterbed effect on the grounds that it lacked an economic foundation. ${ }^{2}$

This paper offers a logically consistent foundation for a theory of the waterbed effect. In addition, and possibly more importantly, this paper provides antitrust authorities with guidelines on when to expect such a waterbed effect to be strong and, in particular, even sufficiently strong to lead to a reduction in consumer surplus or welfare. ${ }^{3}$

The theory of the waterbed effect that we develop cautions against what could possibly be a too-positive picture of powerful buyers as 'consumers' champions'. ${ }^{4}$ In principle, the exercise of differential (or asymmetric) buyer power may harm consumers already in the

\footnotetext{
${ }^{*}$ We thank Paul Dobson, Adrian Majumdar, the Editor and two anonymous referees for very helpful comments and discussions. Support from ESRC grant RES-062-23-2099 is gratefully acknowledged.

$\dagger$ University of Frankfurt, Imperial College London and CEPR. E-mail: Roman.Inderst@hof.unifrankfurt.de.

${ }_{\ddagger}^{\ddagger}$ Imperial College London, University of Rome II and CEPR. E-mail: t.valletti@imperial.ac.uk.
} 
short run-i.e., even when the number of firms and the quality and range of their products all remain constant. ${ }^{5}$ While a large and powerful firm improves its own terms of supply by exercising its bargaining power, the terms of its competitors can deteriorate sufficiently so as to ultimately increase average retail prices and, thereby, reduce total consumer surplus. Such consumer detriment from the waterbed effect is more likely if the adversely affected firms are already sufficiently squeezed, due to relatively higher wholesale prices and, consequently, lower market shares.

In our model, buyer power arises from size. ${ }^{6}$ A larger buyer's additional discount allows it to reduce retail prices and, thereby, attract additional business, some of which will be captured at the expense of other, less powerful buyers. As this lowers not only sales volume, but also purchase volume, for the latter firms, their bargaining position vis-à-vis suppliers is further worsened, resulting in less favorable terms of supply. In terms of retail prices, if prices are strategic complements, then for smaller buyers, two conflicting forces are at work. While smaller buyers would optimally like to pass on some of the increase in their wholesale price, they simultaneously face more aggressive competition from the larger buyer, given that the terms of trade of the large buyer have improved. While the latter effect often may be sufficiently strong so that all consumers benefit from the exercise of buyer power, our model also allows us to characterize the opposite circumstances: when the waterbed effect is sufficiently strong to increase even the average prevailing retail price. ${ }^{7}$ In this case, total consumer surplus can decrease through the working of a waterbed effect.

A key presumption in this paper is that more-powerful buyers obtain discounts not only through lump-sum payments (e.g., slotting allowances or listing fees) but also 'at the margin.' The key difference is the following: Only in the latter case should we reasonably expect that better terms of supply are passed on to consumers, even in the short run. For the present theory of the waterbed effect, this is important since, otherwise, the more powerful buyer would not enjoy a more competitive position at the retail market. Recent evidence from the aforementioned investigation into the UK's grocery retail market strongly supports the picture that, at least in this industry and for the UK, discounts are given 'at the margin." ${ }^{8}$ The present model captures this in an admittedly simplistic way, namely through assuming linear wholesale contracts. What is key for our results to hold and our theory of the waterbed effect to apply is simply that better terms of trade result in a more competitive position in the retail market. 
Our analysis contributes to the ongoing debate about the economic implications of non-cost justified discounts that more-powerful buyers can negotiate. Battigalli et al. [2007], Chen [2005], Inderst and Wey [2003, 2007], and Vieira-Montez [2007] all analyze the long-run implications of buyer power on the upstream industry. Inderst and Valletti [2009] study, instead, the implications of a ban on price discrimination on downstream incentives to invest in cost reduction. Earlier contributions by von Ungern-Sternberg [1996] and Dobson and Waterson [1997] analyze when the benefits of lower wholesale prices can outweigh the impact from a further monopolization of the retail market.

Snyder [1996] shows how a large buyer can have a positive externality on other buyers through destabilizing supplier collusion. In Chen [2003], a supplier sets the linear wholesale price for a fringe of small buyers before negotiating with a large buyer. As the large buyer becomes more powerful, which is modeled as a shift in the sharing rule for the Nash bargaining game, the supplier tries to recapture some of the lost profits by selling more to the fringe, which requires it to lower the respective wholesale price. Erutku [2005] takes a similar approach, albeit there the large buyer obtains an exogenously given discount, which provides a measure of his buyer power. Interestingly, there a supplier's optimal 'list' price, from which the large buyer's discount is then deducted, changes non-monotonically in the discount, such that sometimes a negative correlation between a small and a large buyer's wholesale prices may obtain, similar to our waterbed effect.

Matthewson and Winter [1996], Gans and King [2002], and Majumdar [2005] all show that if one buyer or buyer group has a first-mover advantage, then it can benefit at the expense of smaller buyers. In Majumdar [2005], this can also manifest itself, as in our paper, in a more competitive position at the retail market. According to our theory, however, if the market structure remains unchanged, a waterbed effect is only present when the respective buyers are also downstream competitors. ${ }^{9}$ Finally, the present analysis complements that in Inderst [2007], where the focus is on the creation of differences in buyer size, namely through acquisitions or improvement of own efficiency. It is shown that buyers that are already larger have also higher incentives to grow further. In a Hotelling model it is shown that the resulting negative impact on rival firms is amplified by the waterbed effect. Instead, the present model generally derives the foundations of a waterbed effect and obtains implications for consumer surplus and welfare.

The rest of this paper is organized as follows. Section II introduces and analyzes the 
benchmark case of symmetric firms, while Section III provides the main analysis with asymmetric buyers. Section IV compares the implications when size is due to organic growth versus acquisitions. The concluding remarks in Section V pull together the various results so as to provide summary guidelines for policy.

\section{THE BENCHMARK CASE WITH SYMMETRIC BUYERS}

We take the following stylized picture of a market in which downstream firms engage in local competition. There are altogether $n=1, \ldots, N$ symmetric final markets. In each market, two downstream firms - referred to as $A_{n}$ and $B_{n}$ - compete. The case of geographically segmented markets may be particularly applicable to retailing.

For now, each downstream firm has the same constant marginal cost $c \geq 0$. Downstream firms can procure from the same supplier, which operates at constant marginal cost $k \geq 0$. Firms transform one unit of purchased input into one unit of output. The constant input price is given by $w\left(A_{n}\right)$ and $w\left(B_{n}\right)$, respectively. We denote a downstream firm's gross marginal cost (i.e., including the wholesale price) by $m\left(A_{n}\right):=c+w\left(A_{n}\right)$ and $m\left(B_{n}\right):=c+w\left(B_{n}\right)$, respectively. All cost parameters are common knowledge.

In each local market, firms compete in prices, which we denote by $p\left(A_{n}\right)$ and $p\left(B_{n}\right)$, respectively. We further suppose that there is a unique equilibrium in prices and denote the realized profits by $\pi\left(m\left(A_{n}\right), m\left(B_{n}\right)\right)$ for firm $A_{n}$ and, symmetrically, by $\pi\left(m\left(B_{n}\right), m\left(A_{n}\right)\right)$ for firm $B_{n}$. We assume that the derived profit function is strictly decreasing in the marginal cost with $\pi_{1}(\cdot)<0$ for the respective derivatives. In addition, we stipulate that the second derivatives satisfy

$$
\pi_{11}>0 \text { and } \pi_{12}<0 \text {. }
$$

The conditions in (1) are commonly invoked in the literature and are satisfied by many functional specifications (cf. Athey and Schmutzler [2001]).

The existence of a waterbed effect will be independent of whether prices are strategic complements or substitutes. If prices are strategic substitutes, then it is straightforward that the adversely affected downstream firm raises its retail price - following a reduction of its rival's and an increase of its own wholesale price. In what follows, we will, therefore, deal mainly with the more interesting case of strategic complements, implying that, through competition, a countervailing effect arises: while the adversely affected firm would want to 
pass on a higher wholesale price, the fact that its rival's retail price decreases will exert a countervailing force.

Negotiations. Wholesale contracts are determined through simultaneous and publicly observable take-it-or-leave-it offers that the incumbent supplier makes to all downstream firms. ${ }^{10}$ If a downstream firm rejects the supplier's offer, it can access an alternative source of supply. This comes at the additional expenditure $F>0$. Following the seminal contribution of Katz [1987], we may suppose that a downstream firm has the alternative to integrate backwards. In Katz [1987], this alternative is sufficiently attractive for only the largest buyer, while in our analysis it will represent a credible alternative for all downstream firms. In the context of retailing, we may also interpret this alternative as an investment in the production and marketing of a private-label good. ${ }^{11}$ Alternatively, we may suppose that another supplier bids against the incumbent. In this case, the cost $F$ would represent a fixed switching cost, which may also, fully or partially, arise at the supplier. Finally, we can also imagine that, after rejecting the incumbent's offer, a downstream firm has to incur search costs $F$ to locate a new source of supply. When accessing the alternative source of supply, a downstream firm can operate at gross marginal cost i.e., again including the wholesale price - of $m^{A L}:=c+k^{A L}$.

Analysis with Symmetric Buyers. $\quad$ Key to the analysis of wholesale prices are the participation constraints for downstream firms, namely

$$
\left.\pi\left(m\left(A_{n}\right), m\left(B_{n}\right)\right) \geq \pi\left(m^{A L}, m\left(B_{n}\right)\right)\right)-F
$$

for firm $A_{n}$, and

$$
\left.\pi\left(m\left(B_{n}\right), m\left(A_{n}\right)\right) \geq \pi\left(m^{A L}, m\left(A_{n}\right)\right)\right)-F
$$

for firm $B_{n}$. Note that we used for (2) and (3) that in case of rejecting the supplier's offer, the respective downstream firm can operate with gross marginal cost $m^{A L}$, while its rival still operates with gross marginal cost $m\left(A_{n}\right)$ or $m\left(B_{n}\right)$, respectively. The value of the respective outside option is given by the right-hand side of both (2) and (3). ${ }^{12}$

Clearly, the constraints (2) and (3) need not always be binding. In particular, they would not be binding if either $F$ or $k^{A L}$ were sufficiently high, thereby making the alternative supply option sufficiently unattractive. In this case, increasing the wholesale prices 
until the constraints bind would not be optimal for the supplier, given that he would then sell only a very low quantity. We want to exclude this case and focus, instead, on the situation where the alternative option is sufficiently attractive so as to effectively constrain the supplier's optimal choice of wholesale prices. We do this by stipulating that $k^{A L}$ is just equal to the current supplier's marginal cost $k$. For simplicity, we then abbreviate $m^{A L}=m=k+c$. Furthermore, in what follows, we will first keep $F$ sufficiently low. We have the following result.

Proposition 1. Consider the benchmark case in which all downstream firms are symmetric, both in size and own marginal cost $c$. Then, for low $F$ there exists a unique equilibrium. The supplier offers each (independent) firm the same wholesale price $w_{I}$, which is strictly increasing in $F$.

\section{Proof: $\quad$ See Appendix.}

The result that the equilibrium wholesale price for each of the independent downstream firms, $w_{I}$, is strictly increasing in $F$ is intuitive given that this reduces the value of their outside option.

Hotelling Model. Suppose that each (local) market is represented by the mass one of consumers that is distributed uniformly over the unit interval. As is well known, this implies that at an interior solution the mass $y_{n}=1 / 2+\left[p\left(B_{n}\right)-p\left(A_{n}\right)\right] /(2 t)$ of consumers shop at outlet $A_{n}$, where $t$ denotes the unit transportation cost.

Proposition 2. In the Hotelling case, the supplier realizes with each of the symmetric, independent firms a margin of

$$
w_{I}-k=3 t(\sqrt{1+2 F / t}-1)
$$

which is strictly increasing in $F$ and also in $t$.

Proof: $\quad$ See Appendix.

Proposition 2 confirms the comparative result in $F$ from Proposition 1. In addition, we find that the supplier's margin $w_{I}-k$ is strictly higher when there is less competition in the downstream market (given higher 'shoe-leather' costs $t$ ). ${ }^{13}$ The supplier can, thus, set 
higher wholesale prices to extract higher profits that are generated by a less competitive retail market.

\section{DIFFERENTIAL BUYER POWER}

\section{III(i). Wholesale Prices}

To develop the key insights on the waterbed effect, it is sufficient to introduce a single large buyer. We do this by supposing that one buyer now operates $2 \leq n_{L} \leq N$ downstream firms (or outlets in the case of retailing), each in a separate market. Without loss of generality, let this be the owner of firms $A_{n}$ with $n \in\left\{1, \ldots, n_{L}\right\}$.

In equilibrium, there will now be three different wholesale prices. The large buyer obtains a wholesale price $w_{L}$ such that $w\left(A_{n}\right)=w_{L}$ for all $n \in\left\{1, \ldots, n_{L}\right\}$. For the competing small firms in these $n_{L}$ markets, we denote $w\left(B_{n}\right)=w_{S}$ for $n \in\left\{1, \ldots, n_{L}\right\}$. Finally, it is immediate that the wholesale price for all other downstream firms in markets $n>n_{L}$, where the large buyer is not active, will be unaffected by the presence of the larger buyer and will, thus, still be equal to $w_{I}$, as used in Proposition 1 . In analogy to the analysis with symmetric buyers, the three wholesale prices must jointly satisfy the respective participation constraints:

$$
\begin{array}{ll}
\text { for } w_{I}: & \pi\left(m_{I}, m_{I}\right) \geq \pi\left(m, m_{I}\right)-F, \\
\text { for } w_{S}: & \pi\left(m_{S}, m_{L}\right) \geq \pi\left(m, m_{L}\right)-F, \\
\text { for } w_{L}: & n_{L} \pi\left(m_{L}, m_{S}\right) \geq n_{L} \pi\left(m, m_{S}\right)-F .
\end{array}
$$

As in Proposition 1, for low $F$, all participation constraints in (5) bind in equilibrium. This allows us to obtain the following characterization.

Proposition 3. Consider the case in which a large buyer controls several downstream firms in separate markets. The large buyer's wholesale price, $w_{L}$, is then strictly smaller than the (benchmark) wholesale price in case of symmetric buyers, $w_{I}$, from Proposition 1 , while the wholesale price of competing smaller firms, $w_{S}$, is strictly larger than $w_{I}$. Moreover, as the number of firms $n_{L}$ that the large buyer controls increases, $w_{L}$ further decreases, while $w_{S}$ further increases.

Proof: $\quad$ See Appendix. 
Hence, we find a waterbed effect with $w_{L}<w_{I}<w_{S}$. When $n_{L}$ increases, the wholesale price differential, $w_{S}-w_{L}>0$, widens for two reasons: first, as $w_{L}$ decreases and, second, as $w_{S}$ increases.

We now provide more intuition for the results in Proposition 3. The first part is to show that $w_{L}<w_{I}$. When rejecting the incumbent supplier's offer and switching to the alternative source of supply, a buyer incurs the costs $F$. A large buyer, who controls $n_{L}>1$ firms and consequently buys and sells a larger number of units, can spread the costs $F$ over a larger number of units. This forces the supplier to reduce the wholesale price so as to still satisfy the large buyer's participation constraint. Formally, this effect can be seen immediately when transforming the large buyer's binding participation constraint (5) into

$$
\pi\left(m_{L}, m_{S}\right)=\pi\left(m, m_{S}\right)-F / / n_{L} .
$$

Turn next to the wholesale price of small firms that compete with the large buyer. As the large buyer obtains a discount, which he at least partially passes on into lower retail prices, he will take away market share from smaller firms. A first intuition for why the small firms' wholesale price, $w_{S}$, should increase is that, in analogy to the previous argument for the large buyer, a small buyer can now spread the costs $F$ only over a smaller number of units. However, this argument is incomplete as it ignores that the lower retail price of the large buyer's firms, given the large buyer's lower wholesale price, will negatively affect both the value of a smaller firm's outside option, $\pi\left(m, m_{L}\right)$, and the value of his equilibrium payoff under the supplier's offer, $\pi\left(m_{S}, m_{L}\right)$. It turns out, however, that the first effect is stronger: As the rival firm in a given market becomes more competitive, following a reduction in its wholesale price, the (negative) effect on the value of a firm's outside option is stronger, which relaxes the respective participation constraint and, thereby, allows the supplier to raise his wholesale price. This is, in turn, an immediate consequence of the standard property (1) of reduced profit functions.

For such a waterbed effect to arise, it is crucial that the supplier can price discriminate. In our model, this is the case only if $F>0$. As $F$ increases, there is increasing scope for price discrimination, leading to a widening of wholesale price differentials.

Corollary 1. While both wholesale prices, $w_{L}$ and $w_{S}$, strictly increase with $F$, also the difference $w_{S}-w_{L}>0$ strictly increases.

Proof: $\quad$ See Appendix. 
Note that for our theory of the waterbed effect to apply, the adversely affected small firms must be in competition with the firms that are controlled by the large buyer. This is the case for all outlets $B_{n}$ in markets $n \leq n_{L}$. In contrast, the wholesale price of all other firms, namely in markets $n>n_{L}$, is not affected.

\section{III(ii). Retail Prices and Consumer Surplus}

For a given reduction in the large buyer's wholesale price, $w_{L}$, the corresponding change for small buyers is obtained by moving along their binding participation constraint in (5). Denote the respective retail prices by $p_{L}$ and $p_{S}$, such that along this trajectory we have, from total differentiation, the following marginal impact on small buyers' retail prices:

$$
\frac{d p_{S}}{d w_{L}}=\frac{\partial p_{S}}{\partial w_{L}}+\frac{d p_{S}}{d w_{S}} \frac{d w_{S}}{d w_{L}}
$$

The fact that the first term in (6) is positive while the second term is negative capture two conflicting effects: First, with strategic substitutes $\partial p_{S} / \partial w_{L}>0$ describes the response of small firms to the large buyer's lower wholesale price, given that this induces the large buyer to lower his retail price, $p_{L}$; and, second, $d w_{S} / d w_{L}<0$ and $d p_{S} / d w_{S}>0$ jointly illustrate the impact from the waterbed effect. Consequently, if we had that

$$
\frac{\partial p_{S}}{\partial w_{L}}<-\frac{d p_{S}}{d w_{S}} \frac{d w_{S}}{d w_{L}}
$$

then the waterbed effect would dominate, leading to an increase in small firms' retail prices. Instead, if the converse of (7) holds along the whole trajectory, then, following a reduction in $w_{L}$, all retail prices decrease, despite the working of the waterbed effect.

For the general analysis, we can show that if $F$ is sufficiently small, such that there is altogether little scope for wholesale price discrimination, then any further growth of the large buyer (i.e., an increase in $n_{L}$ ) will reduce all retail prices.

Proposition 4. Suppose that the large buyer's advantage $w_{S}-w_{L}>0$ is sufficiently small, which is the case when $F$ is small such that there is little scope for the supplier to set discriminatory wholesale prices. Then, an increase in the large buyer's size, through the acquisition of additional firms (higher $n_{L}$ ), leads to a reduction of all retail prices, despite the presence of a waterbed effect.

Proof: $\quad$ See Appendix. 
Hotelling Model. With Hotelling competition, the total derivative in (6) becomes

$$
\frac{d p_{S}}{d w_{L}}=\frac{1}{3}\left(1+2 \frac{d w_{S}}{d w_{L}}\right)
$$

Hence, the waterbed effect now dominates, such that condition (7) holds, whenever

$$
\frac{d w_{S}}{d w_{L}}<-\frac{1}{2}
$$

In words, the small firms' retail price decreases if due to the waterbed effect their wholesale price, $w_{S}$, increases by at least half of the reduction in $w_{L}$. From implicit differentiation of the binding participation constraints we now obtain explicitly that

$$
\frac{d w_{S}}{d w_{L}}=-\frac{w_{S}-k}{3 t+w_{L}-w_{S}}=-\frac{1}{6 t} \frac{w_{S}-k}{y_{S}}<0,
$$

where $y_{S}$ is the equilibrium market share of the small firm. ${ }^{14}$ Note that the waterbed effect is stronger when smaller firms are already more disadvantaged (or 'squeezed'), given that they have small market shares (low $y_{S}$ ) and have to pay high wholesale prices. In this case $p_{S}$ can increase. Precisely, from (8) and (9) the respective condition is that

$$
y_{S}<\frac{w_{S}-k}{3 t} \text {. }
$$

Proposition 5. In the Hotelling model, the waterbed effect is stronger if the difference $w_{S}-w_{L}>0$ is already sufficiently large, implying a small market share $y_{S}$ of the small firm. When (10) holds, then the waterbed effect dominates the more intense price pressure from the larger rival, resulting in a higher retail price $p_{S}$. Condition (10) holds only if the large buyer controls sufficiently many outlets (large $n_{L}$ ), competition is sufficiently intense (low $t$ ), and $F$ is not too low. If the converse of (10) holds strictly, instead, then all retail prices decrease, following a (size-induced) marginal reduction of the wholesale price of the larger buyer.

Proof: $\quad$ See Appendix.

Summing up, the waterbed effect must be sufficiently large to give rise to possible policy concerns, which in turn holds only if the large buyer's advantage is already sufficiently substantial. For this to hold, it is in turn necessary that the large buyer is sufficiently larger in size (high $n_{L}$ ), while we also know that higher values $F>0$ provide more scope for price discrimination in the first place. ${ }^{15}$ 
Total demand is inelastic in the Hotelling model. The (marginal) change in consumer surplus, $C S$, is given by the (marginal) change in the average retail price: ${ }^{16}$

$$
\frac{d C S}{d w_{L}}=-\left[y_{S}\left(\frac{\partial p_{S}}{\partial w_{L}}+\frac{d p_{S}}{d w_{S}} \frac{d w_{S}}{d w_{L}}\right)+\left(1-y_{S}\right)\left(\frac{\partial p_{L}}{\partial w_{L}}+\frac{d p_{L}}{d w_{S}} \frac{d w_{S}}{d w_{L}}\right)\right] .
$$

Substituting again for the explicit expressions in the case of the Hotelling model, we obtain that, through the waterbed effect, total consumer surplus is lower if

$$
2 y_{S} \frac{2-y_{S}}{1+y_{S}}<\frac{w_{S}-k}{3 t} .
$$

Condition (12) is clearly stricter than condition (10), which ensured only that small firms' retail prices increase. Note next that, given $y_{S} \leq 1 / 2$, condition (12) is again more easily satisfied when small firms are more disadvantaged, leading to a lower market share $y_{S}$ and a relatively higher wholesale price $w_{S}$.

Proposition 6. In analogy to Proposition 5, the waterbed effect is sufficiently strong to increase even the average retail price and, thus, decrease consumer surplus in the Hotelling model if condition (12) is satisfied. This holds again only if $n_{L}$ and $F$ are both sufficiently large, while $t$ is sufficiently small, thereby ensuring that the wholesale price difference $w_{S}-w_{L}>0$ is itself already sufficiently large.

Note, finally, that in the Hotelling model, an increase in the large buyer's size, $n_{L}$, always reduces welfare. This holds, as in order to minimize shoe-leather costs, an equal split of each local market between the respective two firms would be efficient. Any strictly positive wholesale price difference will, thus, lead to inefficiencies.

\section{FIRM GROWTH AND THE WATERBED EFFECT}

In the preceding analysis, we captured the growth of one buyer by enlarging the number $n_{L}$ of firms that this buyer controls. In this Section, we consider, instead, the case of 'organic growth' through a firm's improved efficiency. We can show that this still gives rise to a waterbed effect. However, welfare implications will be markedly different.

For the sake of brevity, we return to the case in which each firm is operated independently, which allows us to analyze each of the $N$ markets in isolation. Our departure from the perfectly symmetric case analyzed in Section II is, however, that firms can now differ 
in their marginal costs, where we set without loss of generality $c\left(A_{n}\right)<c\left(B_{n}\right)$. Competing firms' gross marginal costs $m\left(A_{n}\right)$ and $m\left(B_{n}\right)$ may, thus, differ both because their wholesale prices $w\left(A_{n}\right)$ and $w\left(B_{n}\right)$ are different and because they have different costs of operations, $c\left(A_{n}\right)<c\left(B_{n}\right)$. Denote, also, the respective gross marginal costs under the alternative supply option by $m^{A L}\left(A_{n}\right):=k+c\left(A_{n}\right)$ and, likewise for $B_{n}$, by $m^{A L}\left(B_{n}\right):=k+c\left(B_{n}\right)$.

Proposition \%. If differences in firm size are due to differences in their own efficiency, then the insights from Proposition 3 still survive. Precisely, the more efficient and thus larger firm - i.e., $A_{n}$ as $c\left(A_{n}\right)<c\left(B_{n}\right)$ - also obtains a lower wholesale price, $w\left(A_{n}\right)<$ $w\left(B_{n}\right)$, while a further reduction in $c\left(A_{n}\right)$ leads to a further widening of the difference $w\left(B_{n}\right)-w\left(A_{n}\right)>0$, both as $w\left(A_{n}\right)$ decreases and as $w\left(B_{n}\right)$ increases.

Proof: $\quad$ See Appendix.

If firm $A_{n}$ reduces its own marginal cost, then this a positive direct effect on consumer surplus and (gross of investment costs) also on welfare. This positive effect would, however, exist even without discriminatory wholesale prices - i.e., if $F=0$ in the present model. For $F>0$, the more efficient firm enjoys, however, an additional comparative advantage as its wholesale price is lower than that of the rival firm. This induces a further shift of market share to the more efficient firm. As is well known, for $c\left(A_{n}\right)<c\left(B_{n}\right)$ but $w\left(A_{n}\right)=w\left(B_{n}\right)=w$ the market share for the more efficient firm is too low from the perspective of maximizing efficiency. This holds, as the more efficient firm optimally does not fully pass on its efficiency advantage, but charges, instead, a higher margin. For low values of $F$, where the difference $w\left(B_{n}\right)-w\left(A_{n}\right)>0$ is still small, we have the following key difference between the case with acquisitions and that with growth through a firm's improved efficiency.

Proposition 8. In the Hotelling model, if one buyer is larger only because he owns more firms through prior acquisitions, then an increase in $F$, which creates more scope for the supplier to set discriminatory wholesale prices, reduces welfare. Instead, if a buyer is larger as he is more efficient, then, at least for low $F$, the resulting larger wholesale price difference improves welfare.

Proof. See Appendix. 
It should be noted that irrespective of whether a buyer obtains an additional discount either through further acquisitions or after improving its own efficiency, this discount is not justified by any additional savings or improved efficiencies on the wholesale side. Hence, from an antitrust perspective, the two cases in Proposition 8 would, in principle, not receive different treatment. Proposition 8 suggests, however, at least from a welfare perspective, a different impact.

\section{CONCLUSION}

The present paper introduces a formal model of a 'waterbed effect' that arises from the exercise of asymmetric buyer power. Key to our theory of the waterbed effect is the interaction of the horizontal and the vertical dimensions: The waterbed effect arises only if buyers compete in the downstream market and if size leads to an additional discount.

The simple model, in particular with the explicit calculations for the linear (Hotelling) model, allowed us to derive a number of more quantitative predictions on the strength of the waterbed effect. When downstream firms compete in strategic substitutes, the exercise of buyer power can still lower all retail prices, despite the presence of a waterbed effect. We found that this is more likely if presently the supplier has little scope to price discriminate or if presently size differences between competing firms are not yet sufficiently large.

The present theory provides the following guidance on when a waterbed effect could be more powerful, leading to aggregate consumer detriment even though the retail price of the powerful buyer decreases. This is more likely if discounts are given more 'at the margin,' where they matter for firms' competitive position. Consumer harm is also more likely if the supplier has substantial scope to price discriminate, as he has a more uncontested position vis-à-vis other sources of supply and if, in addition, downstream firms' present size difference provides substantial grounds to set discriminatory wholesale prices.

The analysis also revealed an important difference when wholesale price discounts are obtained based on size differences that were created from acquisitions and when size differences were due to growth by improved efficiency. In the latter case, discriminatory wholesale prices may have the potential to improve efficiency, provided that the difference between rivals is not too large. 


\section{APPENDIX}

Proof of Proposition 1: We start with some technical observations. We will use throughout that the supplier optimally sets both wholesale prices not below the supplier's marginal cost $k$. (This property is easily established.) Also, we will assume that we can restrict consideration to some bounded interval $[k, \bar{w}]$ such that both $w\left(A_{n}\right)$ and $w\left(B_{n}\right)$ must lie in this interval. Finally, we will assume that derived downstream profit functions are continuous in marginal costs.

We show first that for $F \rightarrow 0$, both $w\left(A_{n}\right)$ and $w\left(B_{n}\right)$ must become arbitrarily close to $k$. Suppose, to the contrary, that along a sequence of equilibria where $F \rightarrow 0$, this would not hold such that the respective values of, say, $w\left(A_{n}\right)>k$ remained bounded away from $k$. Then, the right-hand side of (2) would clearly exceed the left-hand side for all sufficiently low $F$.

We argue next that for sufficiently low values of $F$, it holds from optimality for the supplier that both participation constraints bind. Instead of appealing directly to some concavity restriction imposed on the supplier's problem, our argument assumes only that $F$ shall be small. (Note, however, that this is only a sufficient, but by no means a necessary, assumption.) Denote now for the supplier's profits $\mu\left(m\left(A_{n}\right), m\left(B_{n}\right)\right):=\left(w\left(A_{n}\right)-\right.$ $k) D\left(m\left(A_{n}\right), m\left(B_{n}\right)\right)$ and likewise $\mu\left(m\left(B_{n}\right), m\left(A_{n}\right)\right):=\left(w\left(B_{n}\right)-k\right) D\left(m\left(B_{n}\right), m\left(A_{n}\right)\right)$, where $D(\cdot)$ denotes the by assumption symmetric derived demand function at downstream firms. The supplier's total profit is, thus, given by $\widehat{\mu}\left(m\left(A_{n}\right), m\left(B_{n}\right)\right):=\mu\left(m\left(A_{n}\right), m\left(B_{n}\right)\right)+$ $\mu\left(m\left(B_{n}\right), m\left(A_{n}\right)\right)$.

Clearly, if $w\left(B_{n}\right)=k$ and $m\left(A_{n}\right)$ is sufficiently small, then $d \widehat{\mu}\left(m\left(A_{n}\right), m\left(B_{n}\right)\right) / d m\left(A_{n}\right)>$ 0 . This also clearly extends to the case in which $w\left(B_{n}\right)$ is close to $k$. By these observations, it then follows immediately that for low $F$, at least one participation constraint must bind. Suppose next that only the constraint of $B_{n}$ was binding, but not that of $A_{n}$. When marginally increasing $m\left(A_{n}\right)$ while adjusting $m\left(B_{n}\right)$ to still satisfy the constraint for $A_{n}$ with equality, the supplier's total profits change by

$$
\begin{aligned}
& {\left[D\left(m\left(A_{n}\right), m\left(B_{n}\right)\right)+\left(m\left(A_{n}\right)-k\right) \frac{d D\left(m\left(A_{n}\right), m\left(B_{n}\right)\right)}{d m\left(A_{n}\right)}\right]} \\
& +\left(m\left(B_{n}\right)-k\right) \frac{d D\left(m\left(B_{n}\right), m\left(A_{n}\right)\right)}{d m\left(A_{n}\right)} \frac{d m\left(B_{n}\right)}{d m\left(A_{n}\right)},
\end{aligned}
$$


where

$$
\frac{d m\left(B_{n}\right)}{d m\left(A_{n}\right)}=\frac{d w\left(B_{n}\right)}{d w\left(A_{n}\right)}=\frac{\pi_{2}\left(m, m\left(A_{n}\right)\right)-\pi_{2}\left(m\left(B_{n}\right), m\left(A_{n}\right)\right)}{\pi_{1}\left(m\left(B_{n}\right), m\left(A_{n}\right)\right)} .
$$

Given that, for low $F$, we have that $w\left(B_{n}\right)$ is close to $k$ and, thus, $m\left(B_{n}\right)$ close to $m$, we have that (14) must be close to zero. (We also assume here that both $w\left(B_{n}\right)$ and $w\left(A_{n}\right)$ stay in $[k, \bar{w}]$, which implies that the denominator is bounded away from zero.) By these observations, the sign of (13) is determined by the first expression in rectangular brackets, which for $w\left(A_{n}\right)$ close to $k$ is again always strictly positive.

Thus, we have established that an optimal pair of offers must satisfy the system of the two binding constraints, which we rewrite as

$$
\begin{aligned}
& \left.\pi\left(m, m\left(B_{n}\right)\right)\right)-\pi\left(m\left(A_{n}\right), m\left(B_{n}\right)\right)-F=0 \\
& \left.\pi\left(m, m\left(A_{n}\right)\right)\right)-\pi\left(m\left(B_{n}\right), m\left(A_{n}\right)\right)-F=0 .
\end{aligned}
$$

We show now that, for low $F$, there is only a single solution to (15). A sufficient condition for this to be the case is that the Jacobian matrix of (15) is strictly positive definite. This holds if all principal minors are positive. To see that this is indeed the case, note first that the derivative of the first line of (15) with respect to $m\left(A_{n}\right)$ and the derivative of the second line of $(15)$ with respect to $m\left(B_{n}\right)$ are strictly positive from $-\pi_{1}(\cdot)>0$. Next, the determinant is given by

$$
\begin{aligned}
& \pi_{1}\left(m\left(A_{n}\right), m\left(B_{n}\right)\right) \pi_{1}\left(m\left(B_{n}\right), m\left(A_{n}\right)\right) \\
& \left.\left.-\left[\pi_{2}\left(m, m\left(B_{n}\right)\right)\right)-\pi_{2}\left(m\left(A_{n}\right), m\left(B_{n}\right)\right)\right]\left[\pi_{2}\left(m, m\left(A_{n}\right)\right)\right)-\pi_{2}\left(m\left(B_{n}\right), m\left(A_{n}\right)\right)\right]>0,
\end{aligned}
$$

where the sign holds surely for low $F$, given that the second line goes to zero while the first line remains bounded away from zero. (Note that we assume again that both $m\left(A_{n}\right)$ and $m\left(B_{n}\right)$ must become close to $m$.)

Taken together, we have thus established that in the presently considered symmetric case there is a unique optimal offer to both firms in a given market, $w_{I}$, such that $m_{I}=$ $c+w_{I}$ satisfies

$$
\pi\left(m, m_{I}\right)-\pi\left(m_{I}, m_{I}\right)-F=0 .
$$

Implicit derivation of (16) yields

$$
\frac{d m_{I}}{d F}=\frac{1}{-\pi_{1}\left(m_{I}, m_{I}\right)+\left[\pi_{2}\left(m, m_{I}\right)-\pi_{2}\left(m_{I}, m_{I}\right)\right]}>0 .
$$


Note that in order to sign (17), we could assume that $\pi_{1}<0$ and that $F$ becomes small, which allows us to ignore the second term in the denominator. However, from condition (1), (17) generally holds as, given that $m_{I}>m$ and $\pi_{12}<0$, we have also that $\pi_{2}\left(m, m_{I}\right)-$ $\pi_{2}\left(m_{I}, m_{I}\right)>0$.

Q.E.D.

Proof of Proposition 2: If there is an equilibrium in which market $n$ is fully covered and both firms are active, the equilibrium price of firm $A_{n}$ is

$$
p\left(A_{n}\right)=t+\frac{2 m\left(A_{n}\right)+m\left(B_{n}\right)}{3}
$$

while profits of $A_{n}$ are given by

$$
\pi\left(m\left(A_{n}\right), m\left(B_{n}\right)\right)=\frac{1}{2 t}\left[t+\frac{m\left(B_{n}\right)-m\left(A_{n}\right)}{3}\right]^{2} .
$$

Substituting this into (16), we have the requirement that

$$
\left(w_{I}-k\right)^{2}+6 t\left(w_{I}-k\right)=18 t F
$$

which transforms to (4). It is immediate that (4) is strictly decreasing in F. Differentiating (4) with respect to $t$, we have next that

$$
\frac{d w_{I}}{d t}=3 \frac{3 F-\left(w_{I}-k\right)}{3 t+\left(w_{I}-k\right)}>0
$$

where we assume from $(18)$ that $3 F>w_{I}-k$.

Q.E.D.

Proof of Proposition 3: The argument why, for low F, the optimal pair of offers is characterized again by the system of binding constraints and why this has a unique solution is perfectly analogous to that in the proof of Proposition 1 and is, therefore, omitted. Denote now for convenience $F_{L}:=F / n_{L}$ such that the binding constraints become

$$
\begin{aligned}
\pi\left(m, m_{L}\right)-\pi\left(m_{S}, m_{L}\right)-F & =0 \\
\pi\left(m, m_{S}\right)-\pi\left(m_{L}, m_{S}\right)-F_{L} & =0 .
\end{aligned}
$$

Total differentiation of (20) yields

$$
\left(\begin{array}{cc}
-\pi_{1}\left(m_{S}, m_{L}\right) & \pi_{2}\left(m, m_{L}\right)-\pi_{2}\left(m_{S}, m_{L}\right) \\
\pi_{2}\left(m, m_{S}\right)-\pi_{2}\left(m_{L}, m_{S}\right) & -\pi_{1}\left(m_{L}, m_{S}\right)
\end{array}\right)\left(\begin{array}{c}
d m_{S} \\
d m_{L}
\end{array}\right)=\left(\begin{array}{c}
0 \\
1
\end{array}\right) d F_{L}
$$


such that by Cramer's rule

$$
\begin{aligned}
\frac{d m_{L}}{d F_{L}} & =\frac{-\pi_{1}\left(m_{S}, m_{L}\right)}{\operatorname{Det}}>0, \\
\frac{d m_{S}}{d F_{L}} & =-\frac{\pi_{2}\left(m, m_{L}\right)-\pi_{2}\left(m_{S}, m_{L}\right)}{\operatorname{Det}}<0 .
\end{aligned}
$$

Note that the signs follow from condition (1) and as the determinant satisfies Det $>0$, which we already showed in the proof of Proposition 1.

Q.E.D.

Proof of Corollary 1: $\quad$ Proceeding now as in the proof of Proposition 3, we have from Cramer's rule that

$$
\begin{aligned}
\frac{d m_{L}}{d F} & =\frac{-\pi_{1}\left(m_{S}, m_{L}\right) / n_{L}-\left[\pi_{2}\left(m, m_{S}\right)-\pi_{2}\left(m_{L}, m_{S}\right)\right]}{\operatorname{Det}}>0, \\
\frac{d m_{S}}{d F} & =\frac{-\pi_{1}\left(m_{L}, m_{S}\right)-\left[\pi_{2}\left(m, m_{L}\right)-\pi_{2}\left(m_{S}, m_{L}\right)\right] / n_{L}}{\text { Det }}>0 .
\end{aligned}
$$

Finally, we have that $d\left(m_{S}-m_{L}\right) / d F>0$ holds if

$$
\begin{array}{r}
\quad-n_{L} \pi_{1}\left(m_{L}, m_{S}\right)-\left[\pi_{2}\left(m, m_{L}\right)-\pi_{2}\left(m_{S}, m_{L}\right)\right] \\
>\quad-\pi_{1}\left(m_{S}, m_{L}\right)-n_{L}\left[\pi_{2}\left(m, m_{S}\right)-\pi_{2}\left(m_{L}, m_{S}\right)\right],
\end{array}
$$

which from $n_{L}>1$ holds surely if $F$ is sufficiently low.

Q.E.D.

Proof of Proposition 4: $\quad$ To evaluate (7), note first that from implicit differentiation of the small firm's binding participation constraint, we have that

$$
\frac{d w_{S}}{d w_{L}}=\frac{d m_{S}}{d m_{L}}=\frac{\pi_{2}\left(m, m_{L}\right)-\pi_{2}\left(m_{S}, m_{L}\right)}{\pi_{1}\left(m_{S}, m_{L}\right)} .
$$

As already noted in the proof of Proposition 1, where we used the same expression in (14), we have from $m_{S} \rightarrow m$ as $F \rightarrow 0$ that $d w_{S} / d w_{L} \rightarrow 0$. This implies that for the converse of (7) to hold strictly for low $F$, we only need that $d p_{S} / d w_{L}>0$, where we use condition (1), must remain bounded away from zero.

Q.E.D.

Proof of Proposition 5: As the assertion uses Corollary 1 also for costs $F$ that are not close to zero, we have to establish that the result also holds more generally with Hotelling competition. Substituting the respective expressions into requirement (21), we have after some transformations that

$$
n_{L}\left[3 t+m_{S}-m\right]>3 t+m_{L}-m .
$$


Note first that for $n_{L}=1$, this holds just with equality, as in this case we have also that $m_{S}=m_{L}$. Condition (22) thus holds for all $n_{L}>1$ as $m_{S}$ is strictly increasing and $m_{L}$ strictly decreasing in $n_{L}$.

Next, note that we obtain for the Hotelling case the two participation constraints

$$
\begin{aligned}
& 2\left(w_{S}-k\right)\left(w_{L}-k\right)+6 t\left(w_{S}-k\right)-\left(w_{S}-k\right)^{2}=18 t F \\
& 2\left(w_{S}-k\right)\left(w_{L}-k\right)+6 t\left(w_{L}-k\right)-\left(w_{L}-k\right)^{2}=18 t F / n_{L}
\end{aligned}
$$

from which the respective derivatives in the main text follow immediate. Observe also that from Corollary 1 and Proposition 3 we generally have that both $w_{S}$ and $w_{S}-w_{L}$ increase in $F$ and $n_{L}$. Hence, in the Hotelling model, $y_{S}$ decreases (i.e., the left-hand side of condition (10)), while $\left(w_{S}-k\right) /(3 t)$ increases (i.e., the right-hand side of condition (10)) as $F$ or $n_{L}$ increase. Note next that at $F=0$, the converse of (10) holds strictly, given that then $y_{S}=0.5$ and $w_{S}-k=0$. As we now increase $F$, we ask whether there exists a threshold $F^{\prime}$ such that from $F>F^{\prime}$ condition (10) holds. For this we can transform condition (10) to $3 t<3\left(w_{S}-k\right)-\left(w_{L}-k\right)$, while noting that, for any given $F$, we have $w_{L}-k \rightarrow 0$ as $n_{L} \rightarrow \infty$, such that in the limit the condition transforms to $t<w_{S}-k$.

Note once more that for Proposition 5 we restrict consideration to the case where both firms' participation constraints bind, which is always the case when $F$ is not too large. This, however, leaves open the question whether at least for some of these values of $F$ condition (10), which ensures that the waterbed effect is sufficiently strong, can still be satisfied. While we have numerically checked for a range of examples that this is indeed the case, at least for the limit when the large firm becomes arbitrarily large $\left(n_{L} \rightarrow \infty\right)$ we can tackle this question explicitly.

When $n_{L} \rightarrow \infty$, then $w_{L}=k$ and the participation constraint for the large firm is binding for sure. The problem of the input supplier simplifies to

$$
\max _{w_{S}} \Pi=n_{L}\left[\left(w_{L}-k\right) y_{L}+\left(w_{S}-k\right) y_{S}\right]=n_{L}\left(w_{S}-k\right) y_{S}
$$

subject to

$$
\begin{aligned}
C_{S} & =2\left(w_{S}-k\right)\left(w_{L}-k\right)+6 t\left(w_{S}-k\right)-\left(w_{S}-k\right)^{2}-18 t F \geq 0, \\
y_{L} & =\frac{1}{2}+\frac{w_{S}-w_{L}}{6 t}=1-y_{S} .
\end{aligned}
$$


The corresponding Lagrangean problem is

$$
\begin{aligned}
\max _{w_{S}, \lambda_{S}} L & =\Pi-\lambda_{S} C_{S} \\
\lambda_{S} & \geq 0, \lambda_{S} C_{S}=0 .
\end{aligned}
$$

with associated Kuhn-Tucker conditions, where $\lambda_{S}$ is the multiplier associated to firm $S$ 's participation constraint, $C_{S}$. This problem can be solved directly obtaining:

$$
\lambda_{S}=n_{L} \frac{2-\frac{1}{\sqrt{1-2 F / t}}}{12 t},
$$

which is positive when $1-2 F / t>1 / 4$, or $F / t<3 / 8$. This proves that, in this range, both constraints are binding. Also, we can obtain the explicit expression for the small firm's input price

$$
w_{S}=k+3 t(1-\sqrt{1-2 F / t})
$$

Since in this case the large and the small firm are charged different wholesale prices, this is now used also to check when $t<w_{S}-k$, i.e., when condition (10) holds. After substitution, this is satisfied in a relevant range, i.e., $F / t>F^{\prime}=5 / 18$. To sum up, both participation constraints bind and the waterbed effect is sufficiently strong if and only if $5 / 18<F / t<3 / 8$, which is non-emtpy.

Q.E.D.

Proof of Proposition 7: With the additional notation at hand, the participation constraints (2) and (3) now become

$$
\left.\pi\left(m\left(A_{n}\right), m\left(B_{n}\right)\right) \geq \pi\left(m^{A L}\left(A_{n}\right), m\left(B_{n}\right)\right)\right)-F
$$

for firm $A_{n}$ and

$$
\left.\pi\left(m\left(B_{n}\right), m\left(A_{n}\right)\right) \geq \pi\left(m^{A L}\left(B_{n}\right), m\left(A_{n}\right)\right)\right)-F
$$

for firm $B_{n}$. Total differentiation of the binding constraints, as previously done for (20), yields now

$$
\begin{aligned}
& \left(\begin{array}{cc}
-\pi_{1}\left(m\left(A_{n}\right), m\left(B_{n}\right)\right) & \pi_{2}\left(m^{A L}\left(A_{n}\right), m\left(B_{n}\right)\right)-\pi_{2}\left(m\left(A_{n}\right), m\left(B_{n}\right)\right) \\
\pi_{2}\left(m^{A L}\left(B_{n}\right), m\left(A_{n}\right)\right)-\pi_{2}\left(m\left(B_{n}\right), m\left(A_{n}\right)\right) & -\pi_{1}\left(m\left(B_{n}\right), m\left(A_{n}\right)\right)
\end{array}\right) \\
& \cdot\left(\begin{array}{c}
d w\left(A_{n}\right) \\
d w\left(B_{n}\right)
\end{array}\right) \\
= & -\left(\begin{array}{c}
\pi_{1}\left(m^{A L}\left(A_{n}\right), m\left(B_{n}\right)-\pi_{1}\left(m\left(A_{n}\right), m\left(B_{n}\right)\right)\right. \\
\pi_{2}\left(m^{A L}\left(B_{n}\right), m\left(A_{n}\right)\right)-\pi_{2}\left(m\left(B_{n}\right), m\left(A_{n}\right)\right)
\end{array}\right) d c\left(A_{n}\right) .
\end{aligned}
$$


Note here again that, in particular, $m\left(A_{n}\right)=w\left(A_{n}\right)+c\left(A_{n}\right)$ and $m^{A L}\left(A_{n}\right)=k+c\left(A_{n}\right)$.

Thus, we have from Cramer's rule that $\frac{d w\left(A_{n}\right)}{d c\left(A_{n}\right)}=-\frac{D_{A}}{D e t}$, where $D_{A}$ is given by

$$
\begin{aligned}
& -\pi_{1}\left(m\left(B_{n}\right), m\left(A_{n}\right)\right)\left[\pi_{1}\left(m^{A L}\left(A_{n}\right), m\left(B_{n}\right)-\pi_{1}\left(m\left(A_{n}\right), m\left(B_{n}\right)\right)\right]\right. \\
& -\left[\pi_{2}\left(m^{A L}\left(A_{n}\right), m\left(B_{n}\right)\right)-\pi_{2}\left(m\left(A_{n}\right), m\left(B_{n}\right)\right)\right]\left[\pi_{2}\left(m^{A L}\left(B_{n}\right), m\left(A_{n}\right)\right)-\pi_{2}\left(m\left(B_{n}\right), m\left(A_{n}\right)\right)\right] .
\end{aligned}
$$

For $d w\left(A_{n}\right) / d c\left(A_{n}\right)>0$ to hold, we thus only need to show that

$$
\pi_{1}\left(m^{A L}\left(A_{n}\right), m\left(B_{n}\right)-\pi_{1}\left(m\left(A_{n}\right), m\left(B_{n}\right)\right)<0\right.
$$

which follows from $\pi_{11}>0$ in (1) together with $m^{A L}\left(A_{n}\right)<m\left(A_{n}\right)$ due to $w\left(A_{n}\right)>k$. Next, we have that $\frac{d w\left(B_{n}\right)}{d c\left(A_{n}\right)}=-\frac{D_{B}}{D e t}$, where now $D_{B}$ is given by

$$
\begin{aligned}
& \pi_{1}\left(m\left(A_{n}\right), m\left(B_{n}\right)\right)\left[\pi_{2}\left(m^{A L}\left(B_{n}\right), m\left(A_{n}\right)\right)-\pi_{2}\left(m\left(B_{n}\right), m\left(A_{n}\right)\right)\right] \\
& -\left[\pi_{1}\left(m^{A L}\left(A_{n}\right), m\left(B_{n}\right)-\pi_{1}\left(m\left(A_{n}\right), m\left(B_{n}\right)\right)\right]\left[\pi_{2}\left(m^{A L}\left(B_{n}\right), m\left(A_{n}\right)\right)-\pi_{2}\left(m\left(B_{n}\right), m\left(A_{n}\right)\right)\right] .\right.
\end{aligned}
$$

To obtain $D_{B}>0$ and, thus, $d w\left(B_{n}\right) / d c\left(A_{n}\right)<0$, we can now assume from (1) that $\pi_{12}<0$.

Q.E.D.

Proof of Proposition 8: We show that in the Hotelling model, the wholesale price difference is indeed strictly increasing in $F$. For simplicity, we abbreviate $A_{n}$ by $A$ and $B_{n}$ by $B$ and again denote the respective variables by subscripts. The two binding participation constraints are given by

$$
\begin{aligned}
& \left(3 t+w_{B}-k+c_{B}-c_{A}\right)^{2}-\left(3 t+w_{B}+c_{B}-w_{A}-c_{A}\right)^{2}=18 t F \\
& \left(3 t+w_{A}-k+c_{A}-c_{B}\right)^{2}-\left(3 t+w_{A}+c_{A}-w_{B}-c_{B}\right)^{2}=18 t F .
\end{aligned}
$$

Note first that the expression for the waterbed effect is, thus, exactly the same as in (9). With Det $>0$ for the determinant and

$$
\frac{d w_{A}}{d F}=\frac{36 t F}{\operatorname{Det}}\left(3 t+c_{A}-w_{B}-k-c_{B}\right)
$$

while the symmetric expression holds for $w_{B}$, we thus have that

$$
\frac{d\left(w_{B}-w_{A}\right)}{d F}=\frac{36 t F}{\operatorname{Det}}\left[2\left(c_{B}-c_{A}\right)+\left(w_{B}-w_{A}\right)\right]>0
$$

Q.E.D. 


\section{REFERENCES}

Athey, S. and Schmutzler, A., 2001, 'Investment and Market Dominance', Rand Journal of Economics, 32, pp. 1-26.

Basker, E., 2005, 'Selling a Cheaper Mousetrap: Wal-Mart's Effect on Retail Prices', Journal of Urban Economics, 58, pp. 203-229.

Basker, E. and Noel, M., 2009, 'The Evolving Food Chain: Competitive Effects of WalMart's Entry into the Supermarket Industry', Journal of Economics and Management Strategy, 18, pp. 977-1009.

Battigalli, P., Fumagalli, C. and Polo, M., 2007, 'Buyer Power and Quality Improvement', Research in Economics, 61, pp. 45-61.

Chen, Z., 2003, 'Dominant Retailers and the Countervailing-Power Hypothesis', Rand Journal of Economics, 34, pp. 612-625.

Chen, Z., 2005, 'Countervailing Power and Product Diversity', mimeo.

Dobson, P. and Waterson, M., 1997, 'Countervailing Power and Consumer Prices', Economic Journal, 107, pp. 418-430.

Erutku, C., 2005, 'Buying Power and Strategic Interactions', Canadian Journal of Economics, 38, pp. 1160-1172.

Foer, A.A., 2007, 'Mr. Magoo Visits Wal-Mart: Finding the Right Lens for Antitrust', Connecticut Law Review, 39, pp. 1307-1335.

Galbraith, J.K., 1952, American Capitalism: The Concept of Countervailing Power (Houghton Mifflin, Boston).

Gans, J.S. and King, S.P., 2002, 'Exclusionary Contracts and Competition for Large Buyers', International Journal of Industrial Organization, 20, pp. 1363-1381.

Inderst, R., 2007, 'Leveraging Buyer Power', International Journal of Industrial Organization, 25, pp. 908-924. 
Inderst, R. and Valletti, T., 2009, 'Price Discrimination in Input Markets', Rand Journal of Economics, 40, pp. 1-19.

Inderst, R. and Wey, C., 2003, 'Bargaining, Mergers, and Technology Choice in Bilaterally Oligopolistic Industries', Rand Journal of Economics, 34, pp. 1-19.

Inderst, R. and Wey, C., 2007, 'Buyer Power and Supplier Incentives', European Economic Review, 51, pp. 647-667.

Katz, M.L., 1987, 'The Welfare Effects of Third Degree Price Discrimination in Intermediate Goods Markets', American Economic Review, 77, pp. 154-167.

Majumdar, A., 2005, 'Waterbed Effects and Buyer Mergers', mimeo.

Matthewson, F. and Winter, R.A., 1996, 'Buyer Groups', International Journal of Industrial Organization, 15, pp. 137-164.

Smith, H. and Thanassoulis, J., 2009, 'Upstream Competition and Downstream Buyer Power', DP 420, Department of Economics, University of Oxford.

Snyder, C.M., 1996, 'A Dynamic Theory of Countervailing Power', Rand Journal of Economics, 27, pp. 747-769.

Vieira-Montez, J., 2007, 'Downstream Concentration and Producer's Capacity Choice', Rand Journal of Economics, 38, pp. 948-966.

von Ungern-Sternberg, T., 1996, 'Countervailing Power Revisited', International Journal of Industrial Organization, 14, pp. 507-520. 


\section{Notes}

${ }^{1}$ Competition Commission [2008], Market Investigation into the Supply of Groceries in the UK, http://www.competition-commission.org.uk/rep_pub/reports/2008/538grocery.htm

${ }^{2}$ For instance, the Office of Fair Trading argued that 'there are theoretical questions that would need to be resolved before concluding that the price differentials observed are evidence of a waterbed effect.' (OFT, The Grocery Market: The OFT's Reasons For Making a Reference to the Competition Commission, London, May 2006 (para. 6.13).)

${ }^{3}$ The president of the American Antitrust Authority, Albert Foer, recently noted: 'The key to competition analysis of Buyer Power may be what is becoming known as the waterbed effect' (Foer [2007], p. 1326). The waterbed effect was also discussed explicitly at the OECD roundtable on buyer power (October 2008) and at the annual conference of the German antitrust authority that was dedicated to buyer power (September 2008).

${ }^{4}$ The most prominent exposition of this idea is arguably Galbraith [1952].

${ }^{5}$ This is a major difference to the 'spiral effect', according to which the exit of less powerful rivals would create scope for a price increase. Compared to the spiral effect theory, that of a waterbed effect seems, by being less prospective, to be more easily testable.

${ }^{6}$ The precise logic for why size creates buyer power will differ somewhat between the case in which size is generated through acquisitions and the case in which size is generated through more-efficient operations.

${ }^{7}$ In fact, in our model, all retail prices will typically be lower if the outlet of the large buyer (chain) has not yet acquired a dominant position in the considered (local) markets. See Basker [2005] and Basker and Noel [2009] on the price impact of an entry by Wal-Mart.

${ }^{8}$ The UK's Competition Commission calculated the relative discount obtained by the largest grocers relative to their smaller rivals, both with respect to the overall net price (i.e., the price net of all payments, whether 'fixed or variable') and with respect to only 'variable' discounts. They found that discounts were larger when considering only the 'variable' components. See Competition Commission [2007], Working Paper on Supplier Pricing, at http://www.competition-commission.org.uk/inquiries/ref2006/grocery/further_working_papers.htm. 
${ }^{9}$ More recently, Smith and Thanassoulis [2009] offer an alternative theory of bargaining in bilateral oligopolies with uncertainty, which can also generate a waterbed effect.

${ }^{10}$ As we showed in the working paper, given the linearity of offers, results hold when individual offers are not observed by other firms and when these hold passive beliefs.

${ }^{11}$ There are many cases in which retail chains have indeed substituted a branded good for a privatelabel alternative. For instance, the German discounter ALDI is famous for this strategy. An alternative strategy, which our model does not intend to capture, is to stock a private-label good next to that of a branded supplier, thereby putting more price pressure on the branded good.

${ }^{12}$ With linear contracts, it is immediate that there would be no scope for mutually profitable renegotiations between the supplier and the single, remaining buyer of his product.

${ }^{13}$ It should be noted, however, that one can not choose the differentiation parameter $t$ arbitrarily small in equation (4) without simultaneously reducing $F$. This is the case as the derivation of the equilibrium relies on the assumption that switching to the alternative supply option represents a credible alternative for both downstream firms. If we let $t \rightarrow 0$ while $F$ remains bounded away from zero, however, then a firm that rejects the offer of $w_{I}$ would, instead, be better off when ceasing operations.

${ }^{14}$ We have $y_{S}:=\frac{3 t+w_{L}-w_{S}}{6 t}$.

${ }^{15}$ As noted previously, however, when $F>0$ becomes sufficiently large, then it is no longer the case that both participation constraints bind. In the proof of Proposition 5 we derive sufficient conditions on $F$ for when indeed both constraints bind.

${ }^{16}$ Formally, denoting by $u$ the gross utility from consuming one unit, total consumer surplus equals

$$
C S:=u-\left[y_{S} p_{S}+y_{L} p_{L}\right]-t\left[\int_{0}^{y_{S}} x d x+\int_{0}^{y_{L}} x d x\right],
$$

which after differentiation with respect to $w_{L}$ yields (11). 